This is an open access article distributed under the terms of the Creative Commons BY-NC-ND Licence

\title{
Influence of girdling on flower sex ratio, biochemical constituents, and fruit set intensity in mango (Mangifera indica L.)
}

\author{
K.S. SHIVASHANKARA*, G.A. GEETHA, and T.K. ROY \\ Division of Plant Physiology and Biochemistry, ICAR-Indian Institute of Horticultural Research, \\ Hessaraghatta Lake Post, Bengaluru, 560 089, India
}

\begin{abstract}
The study was conducted in mango to understand the relationship of various metabolites with flower sex ratio (hermaphrodite/male) and fruit set using stem girdling technique. Girdling one year old branches was carried out in two cultivars, Mangifera indica 'Alphonso' and 'Totapuri' to retain 50, 100 and 150 leaves to vary the content of hormones, sugars, and amino acids. The increased leaf number was found to increase the total sugars, glucose, fructose, and other sugars. Girdling also significantly increased the concentration of abscisic acid (ABA), salicylic acid (SA), jasmonic acid (JA), indole acetic acid, indole butyric acid but decreased gibberellins and cytokinins. Amino acids also increased in the girdled branches. Girdling improved the flower sex ratio as well as fruit set more efficiently in 'Alphonso' than in 'Totapuri'. Results indicate that the increase in production of hermaphrodite flowers may be more related to the higher production of growth inhibitors, like ABA, SA, and JA along with increased concentration of sugars. Increased auxin concentration also might play an important role in increasing the fruit set.
\end{abstract}

Additional key words: sugars, LCMS, amino acids, phytohormones, sugars.

\section{Introduction}

Mango (Mangifera indica L.) is one of the most widely cultivated and popular fruit in tropics and subtropics especially for its economic and nutritive value. Among the horticultural practices, girdling (the removal of a ring of bark/phloem) has been widely applied to increase intensity of flowering, fruit set, and fruit size in number of fruit crops including mango (Williams et al. 2000, Agusti et al. 2005, Williams and Ayars 2005, Rivas et al. 2007, Urban and Alphonsout 2007). Girdling induced effects are rendered by restrictions in the basipetal movement of assimilates through the phloem, resulting in an accumulation of sugars above the girdle portion of the tree (Di Vaio et al. 2001, Murakami et al. 2008, De Schepper et al. 2010, De Schepper and Steppe 2011, Quentin et al. 2013, Lopez et al. 2015). Mango flowering is suggested to involve a leaf synthesized and in phloem mobile florigenic promoter which is synthesized under inductive temperatures and transported to buds for exhibiting floral differentiation (Ramirez et al. 2010a). Florigen is a graft transmissible flowering inducer found to be controlled by the Flowering Locus $T$ in Arabidopsis (Lifschitz et al. 2014). However in tropics, where day and night temperatures do not vary much, floral induction occurs in terminal stems, which have attained sufficient age of at least 4-5 months depending on cultivar (Davenport 2003). The study on the number of leaves required for flowering in 'Keitt' and 'Tommy Atkins' mango trees exposed to tropical conditions revealed that a minimum of $1 / 8$ and $1 / 4$ of leaves per stem were sufficient to induce 6 and $1 \%$ of reproductive shoots with 94 and $99 \%$ of vegetative shoots, respectively (Nunez-Elisea and Davenport 1992, Nunez-Elisea et al. 1996, Davenport 2006, Davenport 2009, Ramirez et al. 2010a, Ramirez and Davenport 2010). Nunez-Elisea and Davenport (1991, 1992) in support found that the complete defoliation of girdled branches during inductive conditions resulted in vegetative shoots instead of generative shoots. Stem age

Submitted 9 November 2018, last revision 5 March 2019, accepted 29 March 2019.

Abbreviations: ABA - abscisic acid; GA - gibberellic acid; LC-MS/MS - liquid chromatography-tandem mass spectrometry; UPLC ultra-performance liquid chromatography.

Acknowledgements: This work is a part of the National Initiative on Climate Resilient Agriculture (NICRA) project funded by the ICAR, New Delhi (F.No.4-3/2010-IA-II), India. The authors are thankful to the director, ICAR-IIHR, Bangalore, for providing the necessary facilities to carry out the experiment.

* Corresponding author; e-mails: shivashankara.ks@icar.gov.in, shivaiihr@yahoo.com 
is also a pre-requisite for reproductive shoot induction, and it proved to be cultivar specific for 'Keitt' and 'Tommy Atkins' trees, minimum five months old shoots are required for induction of flowering in both the cultivars (Ramirez et al. 2010b). Stems must be sufficiently mature, dark green with a minimum age of four to five months for more recalcitrant cultivars to obtain a reproductive shoot (Ramirez et al. 2010b, Ramirez and Davenport 2010).

The sugar economy of plants, more frequently referred to as source-sink relationships, has received considerable attention in recent years (Goldschmidt 1999). However, such research has been conducted mainly with model plants and with a few annual crop plants. Our knowledge and understanding these processes in fruit trees, in particular mango, are still very fragmentary. Through defoliation, girdling and decapitation experiments, Davenport (2006), Ramirez et al. (2010a), Ramirez and Davenport (2010) established the requirement for leaf factors for floral induction in 'Haden' mango. Under such a situation, induction of flowering by stem girdling enhances fruit yield (Urban et al. 2009). Girdling has been shown to modify hormonal status of growing tree. Girdling significantly decreases the levels of trans-zeatin and its riboside, dihydrozeatin and its riboside in xylem sap and increases abscisic acid (ABA) concentration in leaves (Dai and Dong 2011, Kong et al. 2012). Girdling interrupts phloem transport of sugars (Urban and Alphonsout 2007, Murakami et al. 2008; De Schepper and Steppe 2011, Sellin et al. 2013, Lopez et al. 2015), basipetal flow of auxin (Ferguson and Beveridge 2009), and acropetal flow of cytokinin (Havelange et al. 2000, Dai and Dong 2011).

Among fruit trees, girdling has been most frequently used in mango to demonstrate the role of leaves in supplying a floral stimulus (Ramirez et al. 2010a, Ramirez and Davenport 2010). Despite the wide application of girdling in relation to flowering and fruiting, information on its effect on flower sex ratio and metabolite concentrations are limited except a few on hormonal concentrations. The objective of the current study was to understand the effects of girdling on flower sex ratio, fruit set intensity, and changes in the concentrations of phytohormones, growth regulators, sugars, and amino acids in mango 'Alphonso' and 'Totapuri' with a view to find out the relationship between metabolites, sex ratio, and fruit set.

\section{Materials and methods}

The field and laboratory experiments were conducted at Indian Council for Agriculture Research (ICAR) the Indian Institute of Horticultural Research (IIHR), Hessaraghatta, Bengaluru, India, located at $13^{\circ} 08^{\prime} \mathrm{N}$ latitude, $77.29^{\circ} \mathrm{E}$ longitude and $890 \mathrm{~m}$ above mean sea level. The maximum temperature during the experimental period ranged from 25.6 to $31.3{ }^{\circ} \mathrm{C}$ with a mean of $28.3{ }^{\circ} \mathrm{C}$, while the minimum temperature ranged from 14.7 to $19.6^{\circ} \mathrm{C}$ with a mean of $16.8^{\circ} \mathrm{C}$ (Fig. 1 Suppl.). A mean relative humidity was about $63.8 \%$ and no rainfall was observed during the experimental period. Soil was a red sandy loam with a $\mathrm{pH}$ of 5.2-6.4. All the weather particulars were recorded during the experimental period.

The experiment was conducted on two uniformly grown commercially important mango cultivars 'Alphonso' and 'Totapuri'. These cultivars differ in their flowering behaviour. 'Alphonso' is irregular in flowering, whereas 'Totapuri' is regular in flowering. 'Alphonso' as a major table purpose cultivar occupies a larger portion of export market. On the other hand, 'Totapuri' is mainly grown for pulping purpose. Both the cultivars were planted with a spacing of $9 \times 9 \mathrm{~m}$, and each tree was approximately $6 \mathrm{~m}$ in height. Girdling was done by removing the bark of $1.0 \mathrm{~cm}$ width from quaternary $\left(\mathrm{N}_{4}\right)$ branches, which are one year old and have more than one terminal flowering branch. The girdling treatment was done before flower bud differentiation. Three trees were selected for each treatment in both the cultivars. In each tree, a minimum of 20 branches were girdled and the leaves were removed manually, retaining only 50,100 or 150 leaves per treatment. To compare treatments with untreated branches, few branches were considered as a control or non-girdled ones. These branches were not girdled and all the leaves were retained without disturbing its structure. The data were recorded on both non-girdled and girdled branches for flower sex ratio, panicle length, and fruit set. One month after girdling, leaf samples from each treatment were collected for biochemical analyses such as determinations of sugars, phytohormones, growth regulators, and free amino acids. From three replicated trees, six branches i.e., two branches/tree were sampled from each treatment for the biochemical analyses. All the biochemical analyses were done in biological triplicates.

Flower sex ratio: For flower count, panicles were tagged randomly on a tree. A total of 20 flower panicles from three trees were used for counting. Hermaphrodite and staminate flowers were counted daily throughout the flowering period by removing the flowers as and when they opened. Panicle length was recorded using a measuring scale.

Fruit set: Fruit set was calculated by counting the fruits per inflorescence in the remaining panicles at the pea stage of fruit growth. The fruit set percentage was calculated using a following formula: Fruit set $[\%]=$ (number of fruits per inflorescence / number of hermaphrodite flowers per inflorescence) $\times 100$.

Estimation of phytohormones and growth regulators: Extraction and purification of different plant hormones was carried out according to Pan et al. (2008). Plant hormones, like indole acetic acid, indole butyric acid, abscisic acid (ABA), gibberellic acids $\left(\mathrm{GA}_{4}, \mathrm{GA}_{3}\right)$, zeatin, and plant growth regulators, like salicylic acid and jasmonic acid, were analyzed. The phytohormones were extracted using 1-propanol: $\mathrm{H}_{2} \mathrm{O}(2: 1)$ with $0.07 \%(\mathrm{~m} / \mathrm{v})$ $\mathrm{HCl}$. The extract was centrifuged at $10750 \mathrm{~g}$ for $30 \mathrm{~min}$ and the collected supernatant was evaporated to dryness and redissolved in a mobile phase containing $500 \mu \mathrm{L}$ of a mixture of methanol- $0.05 \%(\mathrm{v} / \mathrm{v})$ formic acid (1:1), filtered through $0.2 \mu \mathrm{m}$ nylon filter paper, and $5 \mu \mathrm{L}$ was injected for LC-MS/MS (Liquid chromatography-tandem 
mass spectrometry) analysis. Analytical column used was a 2.1 x $50 \mathrm{~mm}$ UPLC (Ultra Performance Liquid Chromatography) BEH-C18 column (Waters, USA) with $1.7 \mu \mathrm{m}$ particles protected by a vanguard $\mathrm{BEH}-\mathrm{C} 18$ with a $1.7 \mu \mathrm{m}$ particle sized guard column (Waters, USA).

Estimation of sugars: Extraction and purification of different sugars were done as outlined in Steppuhn and Wackers (2004). Various sugars, such as fructose, lactose, fucose, galactose, glucose, arabinose, mannose, ribose, sorbitol, sucrose, and trehalose were assessed. Sugars were extracted using $80 \%(\mathrm{v} / \mathrm{v})$ ethanol and estimated using LC-MS/MS [Waters UPLC H class system fitted with triple quadrupole mass spectrometry MS/MS system]. Analytical column used was $2.1 \times 100 \mathrm{~mm}$ UPLC BEH-amide column (Waters, USA) with $1.7 \mu \mathrm{m}$ particles protected with a vanguard $B E H$-amide with $1.7 \mu \mathrm{m}$ guard column (Waters, USA).

Estimation of free amino acids: Extraction and estimation of free amino acids were carried out as per Nimbalkar et al. (2012) using a methanol $(20 \%, \mathrm{v} / \mathrm{v})$ : formic acid (99.9:0.1) mixture. Free amino acids, like serine, valine, methionine, lysine, arginine, phenylalanine, histidine, tyrosine, citrulline, leucine, and tryptophan were assessed using LC-MS/MS. Analytical column used was a $2.1 \times$ $50 \mathrm{~mm}$ UPLC BEH-C18 column (Waters, USA) with a $1.7 \mu \mathrm{m}$ particle size, protected by a vanguard $B E H C-18$ guard column (Waters, USA).

\section{Statistical analysis}

The experiment was conducted in a completely randomized design with three replicates having 15 plants for each cultivar. Significance among means was analyzed using analysis of variance at $\alpha=0.05$.

\section{Results and discussion}

The removal of a strip of phloem from the trunk by girdling blocks the transport of major plant metabolites to the roots; a large amount of sugars produced by photosynthesis accumulates in vegetative organs above girdle or is utilized for fruit production (Di Vaio et al. 2001, Murakami et al. 2008, De Schepper et al. 2010, De Schepper and Steppe 2011, Quentin et al. 2013, Sellin et al. 2013, Lopez et al. 2015). Hence, a relationship between source and sink may be manipulated by imposing different levels of leaf-to-fruit ratios on girdled branches.

Flower sex ratio: Flower sex ratio (hermaphrodite to staminate) was found to increase in the girdled branches when compared to the non-girdled branches (Fig. 1A) in both the cultivars. However, the increase in flower sex ratio with girdling was significant in 'Alphonso' when compared to 'Totapuri'. Girdling did not show any major difference between the treatments in 'Totapuri'. This may be due to a higher flower sex ratio observed in the control branches itself in 'Totapuri', and also being a regular bearing variety, a response to changes in metabolites may be minimum. An increased production of male strobili was observed in partially girdled Pinus trees; however, female strobili were more in $\mathrm{GA}_{4 / 7}$ treated trees (Vargas-Hernandez and VargasAbonce 2016).

Panicle length: Flower panicle length increased with an increase in the number of leaves, and the longest panicle was observed in 150 leaves (Fig. 1B). Such an effect of girdling could be due to availability of more sugars and auxins in branches with a higher number of leaves. A higher shoot diameter when compared to the control was reported with increasing duration after girdling to be due to an increased accumulation of sugars in pistachio (Vemmos et al. 2012).

Sugars accumulation: Girdling is a well-established technique to disturb sugars allocation within a plant. The effects of girdling, which interrupts basipetal phloem transport, are largely dependent on species, the time of girdling and size of the girdled branch. It is a technique known to favor sugars accumulation in leaves and fruit size increase in trees (Quentin et al. 2013), and generally causes an accumulation of sugars above the girdle and a reduction of sugars in the root system (Urban and

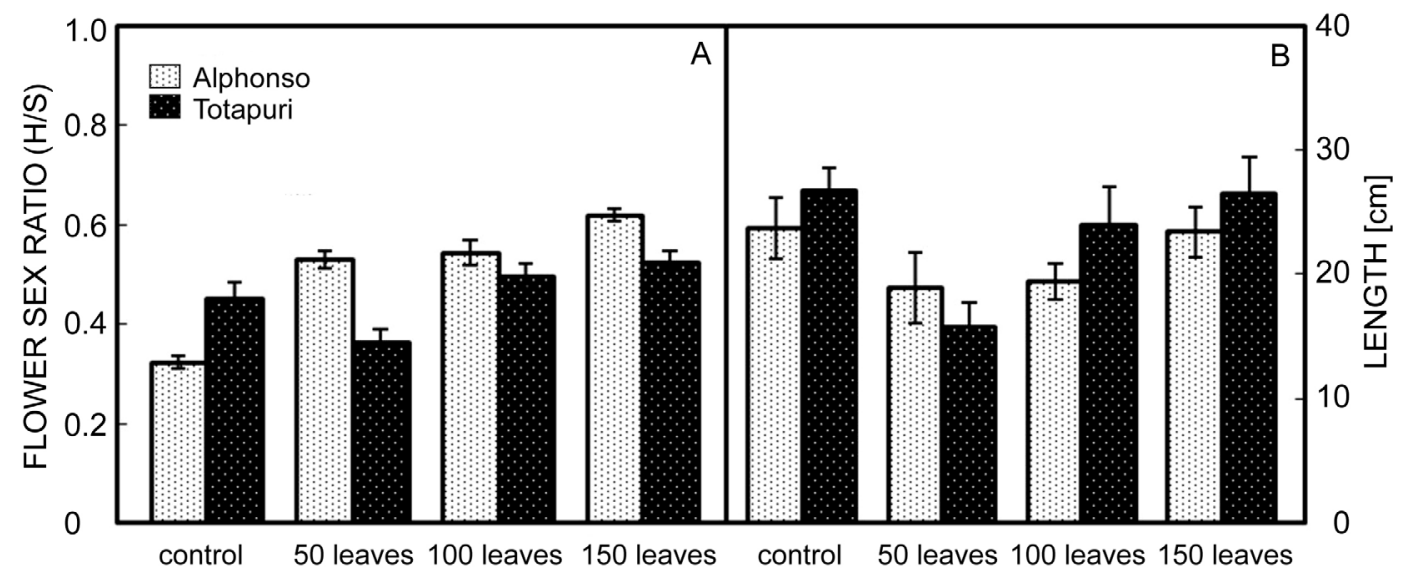

Fig. 1. Flower sex ratio $(A)$ and the size of flower panicles $(B)$ in girdled and non-girdled (control) branches. The branches were girdled to retain 50, 100 and 150 leaves in mango cultivars 'Alphonso' and 'Totapuri'. H/S - Hermaphrodite to staminate flower ratio. 


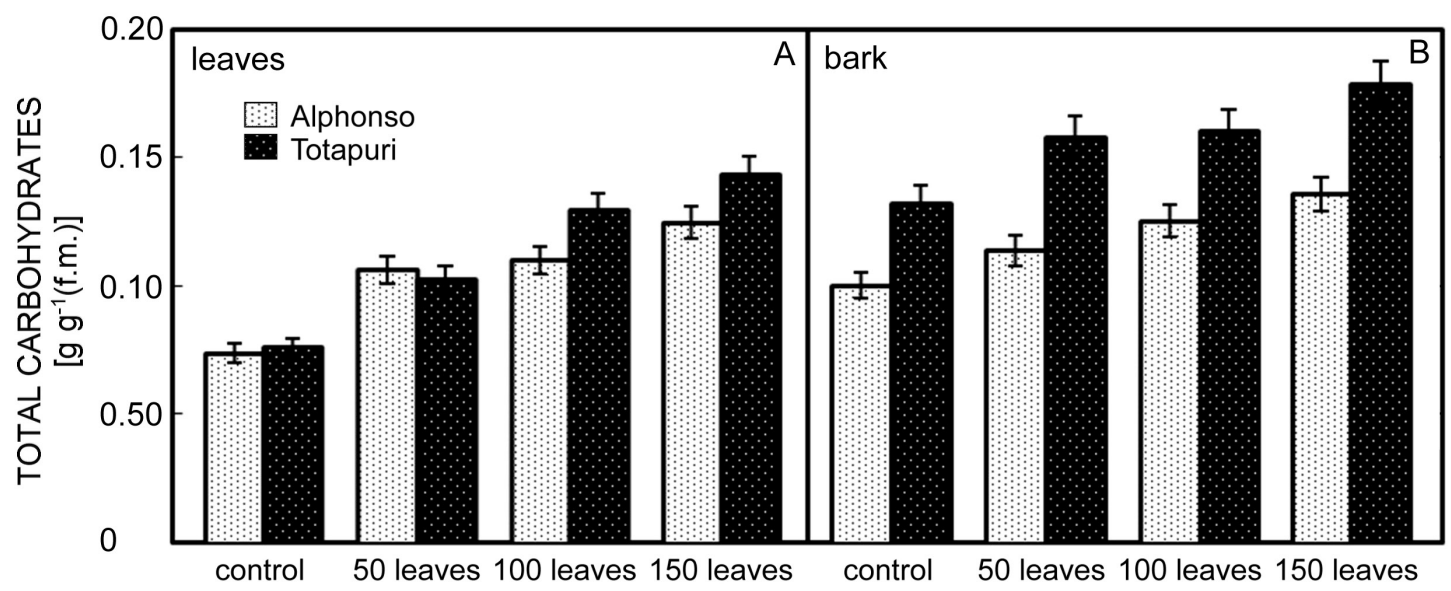

Fig. 2. Total sugars in leaves $(A)$ and bark $(B)$ of girdled (50,100 and 150 leaves) and non-girdled (control) branches in mango cultivars 'Alphonso' and 'Totapuri'.

Lechaudel 2005, Singh et al. 2007, Maunoury-Danger et al. 2010). Our results are in line with the earlier findings; girdled branches accumulate more total sugars in leaves as well as in bark compared to non-girdled branches (Fig. $2 A, 2 B)$. Total sugars increased as the number of leaves increased in the girdled branches. Girdling improves the quality of peach and nectarine fruits (Agusti et al. 1998) and reduces shoot growth (McFadyen et al. 2013). Girdling at the time of panicle emergence increases fruit set by an average of $66 \%$, whereas girdling in mid-September or during the fourth week of October, one or two months after panicle emergence, has no apparent effect on the number of fruits retained (Oosthuyse 1991).

Phytohormones and growth regulators: Girdling breaks the flow of not only sugars but also production and translocation of certain plant hormones. In the present study, major plant hormones, like ABA, indole acetic acid, indole butyric acid, and plant growth regulators like salicylic acid and jasmonic acid, were found to be prominent and consistently increased as the number of leaves increased from 50 to 150, while plant hormones, like $\mathrm{GA}_{3}$ and $\mathrm{GA}_{4}$, and zeatin, decreased in the girdled branches compared to the non-girdled branches (Table 1). In 'Totapuri' a significantly higher salicylic acid, jasmonic acid, and ABA were observed when compared to 'Alphonso'. Girdled plants contain less trans-zeatin and its riboside, dihydrozeatin and its riboside, and isopentenyl adenine and its riboside, but more ABA than control plants in both main stem leaves and xylem sap were observed (Dai and Dong 2011). Rivas et al. (2011) girdled the trunk of mandarin seedlings in spring and found that girdling increases ABA in young leaves and decreased it in mature leaves. Data showed that girdled branches gain the highest ABA content in young leaves, descending in controls, whereas girdling limbs occupy the last position in this respect (Ibrahim et al. 2016). Higher concentrations of auxins in girdled branches may be involved in flowering as reported earlier in the buds of "on" year 'Langra' (Upreti and Murti 1993, Kumar et al. 2014). An increased concentration of auxins above the girdle might be due to the interruption of basipetal movement in the phloem (Ferguson and Beveridge 2009). Similar results were reported in the bark and xylem sap of peach trees (Cutting and Lyne 1993). The $\mathrm{GA}_{3}$ inhibits flowering in many woody perennials (Pharis and King 1985) including mango (Galan-Sauco 1990, Nunez-Elisea and Davenport 1991, Turnbull et al. 1996). Reduction of GA in girdled branches might also trigger flowering (Kong et al. 2012). Chacko (unpublished) showed that the amount of GA like substances were higher in the shoot extracts of 'Dashehari' 'off' season trees as compared with those of 'on' trees.

An increased ratio of auxins/cytokinins in a girdled branch may be involved in the transition of a vegetative bud to a reproductive bud as reported earlier (Dai and Dong 2011). Basipetal movement of auxins is inhibited by stem girdling (Ferguson and Beveridge 2009). Girdling also increases ABA content but decreases cytokinin content (Dai and Dong 2011, Tang et al. 2016). A decrease in GA and an increase in ABA in girdled branches may also improve flowering (Kong et al. 2012). Davenport (2009) stated that phytohormones appear to be responsible for flower initiation in conditions that floral buds are inductive. Our results also reveal that GAs and cytokinins decreased above the girdle region in both the cultivars. Changes in hormone concentrations were probably responsible for the change in sex ratio of flowers. More than a two-fold increase in auxins and $\mathrm{ABA}$, and a similar reduction in $\mathrm{GA}_{4}, \mathrm{GA}_{3}$, and zeatin may play an important role in determining the sex of flowers.

Sugar profiling: Sugar profiling under the varied girdling treatments reveals that the major sugars present were fructose, glucose, sucrose, sorbitol, mannose, and ribose. Glucose, sucrose, fructose, and galactose increased with the increased number of leaves in the girdled branches compared to the non-girdled branches. Total sugar in the non-girdled branches was higher in 'Totapuri' compared to 'Alphonso'. However, after girdling, sugars increased significantly in 'Alphonso'. Sucrose was significantly higher in 'Totapuri' (30 to 50 times) compared to 'Alphonso'. On the other hand, glucose was higher in 'Alphonso' compared 
Table 1. Plant hormones and growth regulators [ng g-1(f.m.)] in the leaves of girdled and non-girdled (control) branches of mango 'Alphonso' and 'Totapuri'. Girdling was done to retain 50, 100, and 150 leaves per branch. SA - salicylic Acid, IAA - indole acetic acid, IBA - indole butyric acid, JA - jasmonic acid, ABA - abscisic acid, $\mathrm{GA}_{4}, \mathrm{GA}_{3}$ - gibberellic acids, LSD - least significant difference, $v$ - cultivars, $t$ - treatments.

\begin{tabular}{llllllllll}
\hline Treatment & Cultivar & SA & IAA & IBA & JA & ABA & GA $_{4}$ & GA $_{3}$ & Zeatin \\
\hline \multirow{2}{*}{ Control } & Alphonso & 1770.10 & 1.09 & 0.22 & 11.20 & 102.150 & 1.39 & 0.51 & 2.65 \\
& Totapuri & 1982.15 & 1.89 & 0.29 & 15.32 & 151.32 & 1.98 & 0.56 & 2.00 \\
\multirow{2}{*}{50 leaves } & Alphonso & 1920.30 & 1.95 & 0.31 & 15.43 & 152.39 & 1.28 & 0.39 & 2.00 \\
& Totapuri & 2148.56 & 2.01 & 0.35 & 19.31 & 181.32 & 1.68 & 0.48 & 1.80 \\
\multirow{2}{*}{100 leaves } & Alphonso & 2832.81 & 2.86 & 0.39 & 21.35 & 192.36 & 0.98 & 0.21 & 1.90 \\
& Totapuri & 2592.63 & 2.85 & 0.39 & 23.42 & 221.52 & 1.20 & 0.31 & 1.20 \\
150 leaves & Alphonso & 3269.13 & 3.79 & 0.40 & 26.22 & 263.26 & 0.74 & 0.09 & 1.20 \\
& Totapuri & 2893.53 & 3.59 & 0.41 & 30.62 & 282.21 & 1.12 & 0.22 & 1.10 \\
Mean & 2426.15 & 2.50 & 0.35 & 20.36 & 193.32 & 1.30 & 0.35 & 1.73 \\
LSD for $v, P \leq 0.05$ & 62.05 & 0.039 & 0.011 & 0.578 & 5.256 & 0.034 & 0.010 & 0.048 \\
LSD for $t, P \leq 0.05$ & 87.75 & 0.056 & 0.015 & 0.817 & 7.433 & 0.049 & 0.014 & 0.068 \\
\multicolumn{2}{l}{ LSD for $v \times t, P \leq 0.05$} & 124.10 & 0.079 & 0.022 & 1.155 & 10.512 & 0.069 & 0.020 & 0.096 \\
\hline
\end{tabular}

Table 2. Sugar profiles $\left[\mu \mathrm{g} \mathrm{g}{ }^{-1}(\mathrm{~d} . \mathrm{m}).\right]$ of leaves from girdled and non-girdled branches of mango 'Alphonso' and 'Totapuri'. LSD - least significant difference, $v$ - cultivars, $t$ - treatments.

\begin{tabular}{|c|c|c|c|c|c|c|c|c|c|c|c|c|}
\hline Treatment & Cultivar & Fructose & Lactose & Fucose & Galactose & Glucose & Arabinose & Mannose & Ribose & Sorbitol & Sucrose & Trehalose \\
\hline \multirow[t]{2}{*}{ Control } & Alphonso & 15699.8 & 6.9 & 13.1 & 102.6 & 14563.7 & 65.9 & 675.3 & 349.5 & 2377.1 & 194.8 & 6.6 \\
\hline & Totapuri & 19741.7 & 4.9 & 7.2 & 150.6 & 7640.0 & 122.7 & 721.4 & 118.2 & 2139.5 & 7322.7 & 38.9 \\
\hline \multirow[t]{2}{*}{50 leaves } & Alphonso & 16172.9 & 7.8 & 7.0 & 154.2 & 17913.8 & 28.0 & 241.4 & 544.8 & 790.0 & 203.3 & 7.1 \\
\hline & Totapuri & 20311.9 & 24.0 & 21.1 & 380.2 & 16469.2 & 111.9 & 107.4 & 302.8 & 482.4 & 12301.3 & 11.1 \\
\hline \multirow[t]{2}{*}{100 leaves } & Alphonso & 34027.7 & 9.6 & 3.9 & 324.7 & 32714.4 & 8.0 & 1537.2 & 191.1 & 1136.9 & 302.7 & 6.8 \\
\hline & Totapuri & 21318.1 & 15.3 & 4.50 & 852.3 & 18046.3 & 26.0 & 1294.4 & 95.8 & 2028.3 & 12587.4 & 29.4 \\
\hline \multirow[t]{2}{*}{150 leaves } & Alphonso & 41678.2 & 3.4 & 0.0 & 922.1 & 38395.8 & 0.0 & 1668.8 & 174.7 & 2196.2 & 325.5 & 20.0 \\
\hline & Totapuri & 27618.4 & 6.0 & 0.0 & 917.8 & 21997.6 & 0.0 & 1393.9 & 63.9 & 2227.3 & 16131.3 & 25.4 \\
\hline \multicolumn{2}{|l|}{ Mean } & 24571.09 & 9.74 & 7.10 & 475.56 & 20967.60 & 45.31 & 954.98 & 230.10 & 1672.21 & 6171.13 & 18.16 \\
\hline \multicolumn{2}{|c|}{ LSD for $v, P \leq 0.05$} & 439.432 & 0.356 & 0.243 & 14.800 & 580.114 & 1.073 & 29.886 & 7.482 & 26.017 & 188.629 & 0.623 \\
\hline \multicolumn{2}{|c|}{$\mathrm{LSD}$ for $t, P \leq 0.05$} & 621.451 & 0.504 & 0.344 & 20.931 & 820.405 & 1.517 & 42.265 & 10.581 & 36.793 & 266.762 & 0.881 \\
\hline \multicolumn{2}{|c|}{$\begin{array}{l}\text { LSD for } v \times t \\
(P \leq 0.05)\end{array}$} & 878.865 & 0.712 & 0.486 & 29.601 & 1160.228 & 2.145 & 59.772 & 14.964 & 52.034 & 377.258 & 1.246 \\
\hline
\end{tabular}

to 'Totapuri' (Table 2). Galactose was a sugar which exhibited a maximum increase in the girdled branches compared to the non-girdled branches in both the cultivars indicating its importance in altering the flower sex ratio. Girdling induced levels of simple sugars, like fructose, glucose, sucrose, and starch are present in spinach, barley, citrus, and sugar maple (Parrott et al. 2007, Murakami et al. 2008, De Schepper and Steppe 2011, Lopez et al.
2015). Girdling also increases sugar content above a girdle region in citrus (Iglesias et al. 2006, Rivas et al. 2006). Higher sucrose, glucose, and fructose amounts were also reported by Murakami et al. (2008) in the leaves of girdled branches than non-girdled branches. The higher increase in flower sex ratio in girdled branches of 'Alphonso' was probably due to a greater increase in fructose, glucose, and galactose amounts 


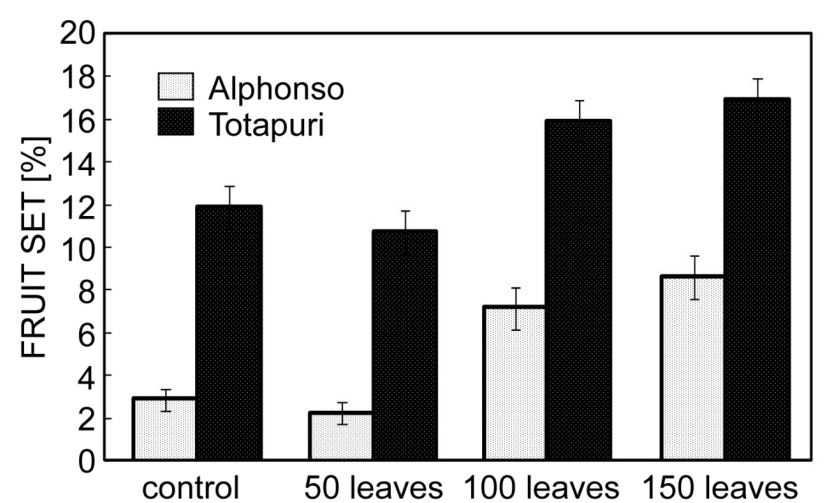

Fig. 3. Fruit set in girdled and control branches of mango 'Alphonso' and 'Totapuri'.

Amino acid profiling: Among different amino acids, phenylalanine, tyrosine, citrulline, leucine, and tryptophan were found to be the major amino acids in mango leaves in the girdling treatment. Tryptophan, phenylalanine, and tyrosine increased in all the girdled treatments compared to the non-girdled treatments, whereas leucine content was high in the non-girdled treatments, decreased in the 50 leaf treatment but increased in the 100 and 150 leaf treatments. The higher aromatic amino acid amounts in the control as well as in girdled branches indicate the importance of phenolic acid biosynthesis in mango and its importance for salicylic acid synthesis (Table 3 ). Phenolic acid pathway is triggered by girdling, leading to salicylic acid and other acids. The increased tryptophan amount also indicates that indole acetic acid biosynthesis increased by girdling.
The amounts of amino acids are significantly higher in differentiated buds compared to undifferentiated buds (Rao et al. 1982, Patil et al. 1992).

Fruit set: The number of fruits per treatment was significantly influenced by girdling and the number of leaves. The highest fruit set at the pea stage were recorded in the 150 leaftreatment followed by the 100 and 50 leaves treatments (Fig. 3). The increase in number per treatment corresponded with the increasing sugars concentration. Fruit set was reported to be influenced by the proportion of hermaphrodite flowers (Geetha et al. 2016, Ramirez and Davenport 2016). The number of fruits retained in a flower panicle increased when girdling was performed at or before flowering compared to branches where girlding was done during the initial fruit set period. This supports the view that the supply of photo-assimilates plays an important role in fruit set and also indicates that girlding should be done well before flower emergence so that sufficient sugars are accumulated above the girdle leading to an increased fruit retention.

\section{Conclusions}

The removal of phloem tissue affects transport of complex organic molecules, such as sugars, amino acids, and hormones, as well as other simpler substances dissolved in the phloem sap. The results of the current study provide new insights into applying a girdling technique on metabolite profiling in relation to fruit set intensity. In the present study, we have considered two commercially important cultivars of mango, which differ in flowering behavior and fruit set but is similar in flower sex ratio. Results reveal

Table 3. Profiling amino acids $\left[\mu \mathrm{g} \mathrm{g}^{-1}(\mathrm{~d} . \mathrm{m}\right.$.) $]$ in the leaves of girdled and non-girdled branches of mango 'Alphonso' and 'Totapuri'. LSD - least significant difference, $v$ - cultivars, $t$ - treatments.

\begin{tabular}{|c|c|c|c|c|c|c|c|c|c|c|c|c|}
\hline Treatment & Cultivar & Ser & Val & Met & Lys & Arg & Phe & His & Tyr & Cit & Leu & $\operatorname{Trp}$ \\
\hline \multirow[t]{2}{*}{ Control } & Alphonso & 0.7 & 19.4 & 0.2 & 2.4 & 1.6 & 122.0 & 19.8 & 140.5 & 34.7 & 56.5 & 277.2 \\
\hline & Totapuri & 0.6 & 40.6 & 0.9 & 2.1 & 2.5 & 103.3 & 7.3 & 155.8 & 23.8 & 120.0 & 323.4 \\
\hline \multirow[t]{2}{*}{50 leaves } & Alphonso & 0.8 & 1.1 & 0.5 & 0.8 & 2.6 & 192.8 & 35.1 & 253.3 & 35.4 & 40.7 & 649.8 \\
\hline & Totapuri & 1.20 & 7.0 & 8.4 & 1.7 & 35.8 & 220.7 & 7.4 & 240.9 & 24.0 & 62.9 & 451.5 \\
\hline \multirow[t]{2}{*}{100 leaves } & Alphonso & 0.2 & 1.6 & 1.1 & 1.0 & 9.9 & 224.0 & 30.3 & 309.3 & 36.2 & 63.8 & 747.2 \\
\hline & Totapuri & 0.4 & 16.3 & 0.0 & 1.2 & 5.8 & 303.3 & 7.4 & 350.9 & 21.5 & 120.5 & 494.6 \\
\hline \multirow[t]{2}{*}{150 leaves } & Alphonso & 0.7 & 1.2 & 0.0 & 1.7 & 2.0 & 317.3 & 10.6 & 376.2 & 26.5 & 73.4 & 768.3 \\
\hline & Totapuri & 1.2 & 87.2 & 0.0 & 2.0 & 54.4 & 327.8 & 5.3 & 439.2 & 19.1 & 188.5 & 659.5 \\
\hline \multicolumn{2}{|l|}{ Mean } & 0.73 & 21.80 & 1.39 & 1.61 & 14.33 & 226.40 & 15.40 & 283.26 & 27.65 & 90.79 & 546.44 \\
\hline \multicolumn{2}{|c|}{ LSD for $v, P \leq 0.05$} & 0.022 & 0.322 & 0.022 & 0.034 & 0.742 & 6.011 & 0.434 & 4.844 & 0.813 & 2.675 & 12.458 \\
\hline \multicolumn{2}{|c|}{$\mathrm{LSD}$ for $t, P \leq 0.05$} & 0.031 & 0.456 & 0.032 & 0.049 & 1.049 & 8.501 & 0.613 & 6.850 & 1.149 & 3.784 & 17.619 \\
\hline \multicolumn{2}{|c|}{$\operatorname{LSD}$ for $v \times t, P \leq 0.05$} & 0.043 & 0.644 & 0.045 & 0.069 & 1.483 & 12.022 & 0.867 & 9.688 & 1.626 & 5.351 & 24.916 \\
\hline
\end{tabular}


that girdling increased the flower sex ratio and fruit set intensity in 'Alphonso' to a greater extent compared to 'Totapuri' by increasing metabolites, like sugars, phytohormones, sugars, and amino acids, above the girdle region. In mango the production of hermaphrodite flowers may be regulated by the ratio of $\mathrm{ABA} / \mathrm{GA}$. On the other hand, fruit set and flower panicle length may be influenced by sugars and auxins.

\section{References}

Agusti, M., Andreu, I., Juan, M., Almela, V., Zacarias, L.: Effects of ringing branches on fruit size and maturity of peach and nectarine cultivars. - J. hort. Sci. Biotech. 73: 530-540, 1998.

Agusti, M., Gariglio, N., Juan, M., Almela, V., Mesejo. C.: Effect of branch scoring on fruit development in loquat. - J. Hort. Sci. Biotech. 80: 370-374, 2005.

Cutting, J.G.M., Lyne, M.C.: Girdling and the reduction in shoot xylem sap concentrations of cytokinins and gibberellins in peach. - J. hort. Sci. 68: 619-626, 1993.

Davenport, T.L.: Management of flowering in three tropical and subtropical fruit tree species. - HortScience 38: 1331-1335, 2003.

Davenport, T.L.: Pruning strategies to maximize tropical mango production from the time of planting to restoration of old orchards. - HortScience 41: 544-548, 2006.

Davenport, T.L.: Reproductive physiology. In: Litz, R.E. (ed.): The Mango: Botany, Production and Uses. $2^{\text {nd }}$ edition. Pp. 97169. CAB International, Wallingford 2009.

De Schepper, V., Steppe, K.: Tree girdling responses simulated by a water and carbon transport model. - Ann. Bot. 108: 11471154, 2011.

De Schepper, V., Steppe, K., Van Labeke, M.C., Lemeur, R.: Detailed analysis of double girdling effects on stem diameter variations and sap flow in young oak trees. - Environ. exp. Bot. 68: 149-156, 2010.

Di Vaio C., Petito, A., Buccheri, M.: Effect of girdling on gas exchanges and leaf mineral content in the "Independence" nectarine. - J. Plant Nutr. 24: 1047-1060, 2001.

Ferguson, B.J., Beveridge, C.A.: Roles for auxin, cytokinin, and strigolactone in regulating shoot branching. - Plant Physiol. 149: 1929-1944, 2009.

Galan-Sauco, V.: [The Tropical Fruit Trees in the Subtropics Avocado, Mango, Litchi.] - Longan Ediciones Mundi-Prensa, Madrid 1990.

Geetha, G.A., Shivashankara, K.S., Reddy, Y.T.N.: Varietal variations in temperature response for hermaphrodite flower production and fruit set in mango (Mangifera indica L). South Afr. J. Bot. 106: 196-203, 2016.

Goldschmidt, E.E.: Carbohydrate supply as a critical factor for citrus fruit development and productivity. - HortScience 34: 1020-1024, 1999.

Havelange, A., Lejeune, P., Bernier, G.: Sucrose/cytokinin interaction in Sinapis alba at floral induction: a shoot-to-rootto-shoot physiological loop. - Physiol. Plant 109: 343-350, 2000.

Ibrahim, M.M., Mohamed, A.O., Mohamed, A.H., Omar, A.A.: Effect of some girdling treatments on fruiting behavior and physio-chemical properties of Washington navel orange trees. - IOSR J. Agr. Veter. Sci. 9: 58-65, 2016.

Iglesias, D.J., Tadeo, F.R., Primo-Millo, E., Talon, M.: Carbohydrate and ethylene levels related to fruitlet drop through abscission zone A in citrus. - Trees. 20: 348-355,
2006.

Dai, J., Dong, H.: Stem girdling influences concentrations of endogenous cytokinins and abscisic acid in relation to leaf senescence in cotton. - Acta Physiol. Plant. 33: 1697-1705, 2011.

Kong, L., Aderkas, P., Owen, S.J., Jaquish, B., Woods, J., Abrams, S.R.: Effects of stem girdling on cone yield and endogenous phytohormones and metabolites in developing long shoots of Douglas-fir (Pseudotsuga menziesii). - New Forest. 43: 491503, 2012.

Kumar, M., Singh, V., Arora, A., Singh, N.: The role of abscisic acid (ABA) in ethylene insensitive Gladiolus (Gladiolus grandiflora Hort.) flower senescence. - Acta Physiol. Plant. 36: 151-159, 2014.

Lifschitz, E., Ayre, B.G., Eshed, Y.: Florigen and anti-florigen - a systemic mechanism for coordinating growth and termination in flowering plants. - Front. Plant Sci. 5: 465, 2014.

Lopez, R., Brossa, R., Gil, L., Pita, P.: Stem girdling evidences a trade-off between cambial activity and sprouting and dramatically reduces plant transpiration due to feedback inhibition of photosynthesis and hormone signalling. - Front. Plant Sci. 6: 285, 2015.

Maunoury-Danger, F., Fresneau, C., Eglin, T., Berveiller, D., François, C., Lelarge-Trouverie, C., Damesin, C.: Impact of carbohydrate supply on stem growth, wood and respired $\mathrm{CO}_{2}$ $\delta 13 \mathrm{C}$ : assessment by experimental girdling. - Tree Physiol. 30: 818-830, 2010.

McFadyen, L., Robertson, D., Sedgley, M., Kristiansen, P., Olesen, T.: Effects of girdling on fruit abscission, yield and shoot growth in macadamia. - Sci. Hort. 164: 172-177, 2013.

Murakami, P.F., Schaberg, P.G., Shane, J.B.: Stem girdling manipulates leaf sugar concentrations and anthocyanin expression in sugar maple trees during autumn. - Tree Physiol. 28: 1467-1473, 2008.

Nimbalkar, M.S., Pai, S.R., Pawar, N.V., Oulkar, D., Dixit, G.B.: Free amino acid profiling in grain Amaranth using LC-MS/ MS. - Food Chem. 134: 2565-2569, 2012.

Nunez-Elisea, R., Davenport, T.L., Caldera, M.L.: Control of bud morphogenesis in mango by girdling, defoliation and temperature modification. - J. Sci. 71: 21-40, 1996.

Nunez-Elisea, R., Davenport, T.L.: Effect of duration of low temperature treatment on flowering of containerized 'Tommy Atkins' mango. - In: Proceedings of the $18^{\text {th }}$ Annu. Meeting of the Plant Growth Regulation. Pp. 39-41. Soc. Amer., Boston 1991.

Nunez-Elisea, R., Davenport, T.L.: Requirement for mature leaves during floral induction and floral transition in developing shoots of mango. - Acta Hort. 296: 33-37, 1992.

Oosthuyse, S.A.: Effect of trunk girdling on the number of fruit retained by bearing Haden mango trees. - Yearbook South Afr. Mango Growth Assoc. 11: 55-56, 1991.

Pan, X., Welti, R., Wang, X.: Simultaneous quantification of major phytohormones and related compounds in crude plant extracts by liquid chromatography-electrospray tandem mass spectrometry. - Phytochemistry 69: 1773-1781, 2008.

Parrott, D.L., McInnerney, K., Feller, U., Fischer, A.M.: Steam girdling of barley (Hordeum vulgare) leaves leads to carbohydrate accumulation and accelerated leaf senescence, facilitating transcriptomic analysis of senescence-associated genes. - New Phytol. 176: 56-69, 2007.

Patil, P.B., Rao, M.M., Basarkar, P.W., Srinivasan, C.N., Nalwadi, U.G.: Physiological and Biochemical factors associated with fruit bud differentiation in Alphonso Mango - Total Free Amino acids. - Kar. J. Agr. Sci. 5: 224-228, 1992.

Pharis, R.P., King, R.W.: Gibberellins and reproductive development in seed plants. - Annu. Rev. Plant Physiol. 36: 
$517-568,1985$.

Quentin, A.G., Close, D.C., Hennen, L.M.H.P., Pinkard, E.A.: Down-regulation of photosynthesis following girdling, but contrasting effects on fruit set and retention, in two sweet cherry cultivars. - Plant Physiol. Biochem. 73: 359-367, 2013.

Ramirez, F., Davenport, T.L., Fischer, G.: The number of leaves required for floral induction and translocation of the florigenic promoter in mango (Mangifera indica L.) in a tropical climate. - Sci. Hort. 123: 443-453, 2010a.

Ramirez, F., Davenport, T.L., Fischer, G., Pinzón, J.C.A.: The stem age required for floral induction of synchronized mango trees in the tropics. - HortScience 45: 1453-1458, 2010 b.

Ramirez, F., Davenport, T.L.: Mango (Mangifera indica L.) flowering physiology. - Sci. Hort. 126: 65-72, 2010.

Ramirez, F., Davenport, T.L.: Mango (Mangifera indica L.) pollination: A review. - Sci. Hort. 203: 158-168, 2016.

Rao, M.M., Ravishankar, H., Bojappa, K.M.: Amino acid composition of shoots of Alphonso mango at pre, during and post-fruit bud differentiation stages. - South Indian Hort. 30: 1-3, 1982.

Rivas, F., Erner, Y., Alos, E., Juan, M., Almela, V., Agusti, M.: Girdling increases carbohydrate availability and fruit-set in citrus cultivars irrespective of parthenocarpic ability. - J. hort. Sci. Biotech. 81: 289-295, 2006.

Rivas, F., Fornes, F., Zacarias, L., Agusti, M.: Changes in carotenoids and ABA contents in citrus leaves in response to girdling. - Sci. Hort. 127: 482-487, 2011.

Rivas, F., Gravina, A., Agusti, M.: Girdling effects on fruit set and quantum yield efficiency of PSII in two Citrus cultivars. - Tree Physiol. 27: 527-535, 2007.

Sellin, A., Niglas, A., Õunapuu, E., Karusion, A.: Impact of phloem girdling on leaf gas exchange and hydraulic conductance in hybrid aspen. - Biol. Plant. 57: 531-539, 2013.

Singh, V.K., Tiwari, A.K.M., Singh, D.K., Pathak, S.M.: Effect of leaf number and area on the fruit growth of regular and biennial bearing mango (Mangifera indica L.) grown under north Indian conditions. - Int. J. Fruit Sci. 6: 77-91, 2007.

Steppuhn, A., Wackers, F.L.: HPLC sugar analysis reveals the nutritional state and the feeding history of parasitoids. - Func. Eco. 18: 812-819, 2004.

Tang, G.L., Li, X.Y., Lin, L.S., Zeng, F.J.: Impact of girdling and leaf removal on Alhagi sparsifolia leaf senescence. - Plant growth Regul. 78: 205-216, 2016.

Turnbull, C.G., Anderson, K.L., Winston, E.C.: Influence of gibberellins treatment on flowering and fruiting patterns in mango. - Aust. J. exp. Agr. 36: 603-611, 1996.

Upreti, K.K., Murti, G.S.R.: Hormonal changes in two mango varieties with differing bearing habits. - Golden Jubilee Symposium - Horticultural Research - Changing Scenario. Bangalore 1993.

Urban, L., Alphonsout, L.: Girdling decreases photosynthetic electron fluxes and induces sustained photoprotection in mango leaves. - Tree Physiol. 27: 345-352, 2007.

Urban, L., Léchaudel, M.: Effect of leaf to fruit ratio on leaf nitrogen content and net photosynthesis in girdled branches of Mangifera indica L. - Trees. 19: 564-571, 2005.

Urban, L.M., Lechaudel, M., Alphonsout, L.: The effect of girdling on flowering and leaf net photosynthesis in mango Cv. Cogshall. - Acta Hort. 820: 251-258, 2009.

Vargas-Hernandez, J.J., Vargas-Abonce, J.I.: Effect of giberellic acid $\left(\mathrm{GA}_{4 / 7}\right)$ and partial stem girdling on induction of reproductive structures in Pinus patula. - Forest Syst. 25: 6373, 2016.

Vemmos, S.N., Papagiannopoulou, A., Coward, S.: Effects of shoot girdling on photosynthetic capacity, leaf carbohydrate, and bud abscission in pistachio (Pistacia vera L.). Photosynthetica 50: 35-48, 2012.

Williams, L.E., Ayars, J.E.: Water use of Thompson Seedless grapevines as affected by the application of gibberellic acid $\left(\mathrm{GA}_{3}\right)$ and trunk girdling - practices to increase berry size. Agr. Forest Meteorol. 129: 85-94, 2005.

Williams, L.E., Retzlaff, W.A., Yang, W., Biscay, P.J., Ebisuda, N.: The effect of girdling on leaf gas exchange, water status and non-structural carbohydrates of field-grown Vitis vinifera L. (cv. Flame Seedless). - Amer. Soc. Enol. Vitic. 51: 49-54, 2000 . 